\title{
Oxidative stress-mediated antibacterial activity of graphene oxide and reduced graphene oxide in Pseudomonas aeruginosa
}

This article was published in the following Dove Press journal:

International Journal of Nanomedicine

29 November 2012

Number of times this article has been viewed

\author{
Sangiliyandi Gurunathan \\ Jae Woong Han \\ Ahmed Abdal Dayem \\ Vasuki Eppakayala \\ Jin-Hoi Kim
}

Department of Animal Biotechnology, Konkuk University, Seoul, South Korea

Correspondence: Sangiliyandi Gurunathan Department of Animal Biotechnology, Konkuk University, I Hwayang-dong, Gwangin-gu, Seoul I43-70I, South Korea Tel +8224503687

Fax +8224585414

Email gsangiliyandi@yahoo.com

Jin-Hoi Kim

Department of Animal Biotechnology, Konkuk University, I Hwayang-dong, Gwangin-gu, Seoul I43-70I, South Korea Tel +82 24503687

Fax +82 24585414

Email jhkim54I@konkuk.ac.kr
Background: Graphene holds great promise for potential use in next-generation electronic and photonic devices due to its unique high carrier mobility, good optical transparency, large surface area, and biocompatibility. The aim of this study was to investigate the antibacterial effects of graphene oxide (GO) and reduced graphene oxide (rGO) in Pseudomonas aeruginosa. In this work, we used a novel reducing agent, betamercaptoethanol (BME), for synthesis of graphene to avoid the use of toxic materials. To uncover the impacts of GO and rGO on human health, the antibacterial activity of two types of graphene-based material toward a bacterial model $P$. aeruginosa was studied and compared.

Methods: The synthesized GO and rGO was characterized by ultraviolet-visible absorption spectroscopy, particle-size analyzer, X-ray diffraction, scanning electron microscopy and Raman spectroscopy. Further, to explain the antimicrobial activity of graphene oxide and reduced graphene oxide, we employed various assays, such as cell growth, cell viability, reactive oxygen species generation, and DNA fragmentation.

Results: Ultraviolet-visible spectra of the samples confirmed the transition of GO into graphene. Dynamic light-scattering analyses showed the average size among the two types of graphene materials. X-ray diffraction data validated the structure of graphene sheets, and high-resolution scanning electron microscopy was employed to investigate the morphologies of prepared graphene. Raman spectroscopy data indicated the removal of oxygen-containing functional groups from the surface of GO and the formation of graphene. The exposure of cells to GO and rGO induced the production of superoxide radical anion and loss of cell viability. Results suggest that the antibacterial activities are contributed to by loss of cell viability, induced oxidative stress, and DNA fragmentation.

Conclusion: The antibacterial activities of GO and $\mathrm{rGO}$ against $P$. aeruginosa were compared. The loss of $P$. aeruginosa viability increased in a dose- and time-dependent manner. Exposure to $\mathrm{GO}$ and $\mathrm{rGO}$ induced significant production of superoxide radical anion compared to control. $\mathrm{GO}$ and rGO showed dose-dependent antibacterial activity against $P$. aeruginosa cells through the generation of reactive oxygen species, leading to cell death, which was further confirmed through resulting nuclear fragmentation. The data presented here are novel in that they prove that $\mathrm{GO}$ and $\mathrm{rGO}$ are effective bactericidal agents against $P$. aeruginosa, which would be used as a future antibacterial agent.

Keywords: graphene oxide, reduced graphene oxide, beta-mercaptoethanol, oxidative stress, antimicrobial activity

\section{Introduction}

Nanotechnology involves the application of nano- or quantum-sized materials that possess unique properties in comparison to bulk materials of similar composition. ${ }^{1}$ 
Environmental carbon-based nanotechnology is a promising area of research due to its potential applications in the fields of sensors, water treatment, and alternative energy. ${ }^{2}$ These excellent properties may be relevant at the nanoscale if graphite can be exfoliated into thin nanoplatelets, and even down to the single graphene-sheet level. ${ }^{3}$ Graphite nanoplatelets have often been made from expanded graphite, which basically is produced from graphite intercalation compounds via rapid evaporation of the intercalant at high temperatures. ${ }^{3}$ Graphene is a single atomic plane of graphite $(\mathrm{Gt})^{4,5}$ that was first obtained from the micromechanical exfoliation of Gt. ${ }^{6}$ From the chemistry point of view, graphene oxide $(\mathrm{GO})$ is a graphene sheet with carboxylic groups at its edges and phenol hydroxyl and epoxide groups on its basal plane. ${ }^{7,8}$ Accordingly, GO can be chemically exfoliated from $\mathrm{GtO} .{ }^{7}$ For production of reduced graphene oxide ( $\mathrm{rGO}$ ), thermal annealing or chemical treatment is needed to eliminate functional groups on GO. ${ }^{9}$ These graphene-related materials exhibit unique electronic, thermal, and mechanical properties, ${ }^{5,10}$ and hold great promise in potential applications, such as nanoelectronics, conductive thin films, supercapacitors, nanosensors, and nanomedicine. ${ }^{6,11}$

In recent times, carbon nanotubes (CNTs) have been widely studied in the biomedical field for drug delivery, biosensing, and molecular imaging. ${ }^{12-14}$ Biomedical properties like pharmacokinetics, toxicity, and cytocompatibility of graphene and GO have not been systematically explored. Yang et $\mathrm{al}^{15}$ have reported pharmacokinetics and biodistribution of graphene functionalized with polyethylene glycol (PEG) and examined its toxicity in mice. Their results revealed that graphene/PEG does not induce appreciable toxicity at an administered dose of $20 \mathrm{mg} / \mathrm{kg}$ for 3 months. PEGylated GO in a physiological solution has been employed in cell imaging and drug delivery. ${ }^{16,17}$ Wang et al ${ }^{18}$ have suggested that dose- and time-dependent cytotoxicity of GO, which can enter the cytoplasm and nucleus, decreases cell adhesion and induces apoptosis. Recently, Akhavan et al ${ }^{19}$ reported the biomedical application of biocompatible glucose-reduced GO in photothermal cancer therapy (without any PEGylation). In addition, other research groups have investigated the application of nanoscale reduced GO-quantum dot nanocomposites in magnetically targeted drug delivery, photothermal therapy, and fluorescence, photoacoustic, and magnetic resonance imaging. ${ }^{20-22}$

Several reports on graphene-related materials are currently available in comparison to other synthetic carbon nanomaterials, such as fullerenes and CNTs. ${ }^{23-27}$ There are some interesting studies explaining the possible mechanisms of graphene-sheet cytotoxicity, eg, the interaction of graphenesheet sharp edges with the cell wall. ${ }^{25}$ Accordingly, the potential and toxic effects of graphene-related materials should be thoroughly evaluated. Recently, there have been some reports describing the strong antibacterial activity of GO. ${ }^{24,25}$ This potent antibacterial has been attributed to membrane stress induced by sharp edges of graphene nanosheets, which may result in physical damage to cell membranes, leading to the loss of bacterial membrane integrity and the leakage of RNA. ${ }^{25}$ Several studies have reported that most carbon-based nanomaterials are cytotoxic to bacteria ${ }^{28-30}$ in a dose-dependent manner. ${ }^{15,26}$ Specifically, single-walled CNTs (SWNTs) show the strongest antimicrobial activity. ${ }^{31-34}$ Liao et $\mathrm{al}^{35}$ reported a concentration-dependent toxicity of GO and graphene in human erythrocytes and skin fibroblasts. Involvement of the reactive oxygen species (ROS) generated by graphene was proposed as one of the main mechanisms for the cytotoxicity of graphene at high concentrations $(100 \mathrm{mg} / \mathrm{mL})$ in neural pheochromocytoma-derived $\mathrm{PC} 12,{ }^{36}$ and the size of GO sheets has an effect on the toxicity of GO of high concentration, ie, larger sheets have better biocompatibility in A549 cells. ${ }^{37}$ The direct-contact interaction of extremely sharp edges of graphene nanowalls with the membrane of cells is also known as one of the mechanisms effectively involved in the cytotoxicity of graphene sheets. ${ }^{38}$ Trapping microorganisms within aggregate-reduced graphene sheets was also suggested as another mechanism for describing the cytotoxicity of graphene sheets, especially in a suspension. ${ }^{38}$ The size-dependent cyto- and genotoxic effects of graphene sheets and nanoplates have been evaluated in human mesenchymal stem cells. ${ }^{39}$

Taking this literature into account, we investigated the antibacterial activity of graphene materials in Pseudomonas aeruginosa, which is a common Gram-negative bacterium that can cause disease in humans and animals. Herein, a systematic study was carried out on the antibacterial activity of graphene materials against $P$. aeruginosa, using cell-growth and viability assays in both saline and rich media. Further, our results suggest that the mechanism of antibacterial activity of GO and rGO depends on oxidative stress, ROS generation, and DNA fragmentation.

\section{Materials and methods Materials}

P. aeruginosa (GS1), a strain obtained from the GS Center for Life Sciences, Coimbatore, India, was characterized based on 16s rRNA technique, and the sequence has been 
submitted to GenBank with the accession number JQ968459. Gt powder was purchased from Sigma-Aldrich (St Louis, $\mathrm{MO})$. Analytical-grade betamercaptoethanol (BME), $\mathrm{NaOH}, \mathrm{KMnO}_{4}$, anhydrous ethanol, $98 \% \mathrm{H}_{2} \mathrm{SO}_{4}, 36 \% \mathrm{HCl}$, and $30 \% \mathrm{H}_{2} \mathrm{O}_{2}$ aqueous solution were also purchased from Sigma-Aldrich and used directly without further purification. All aqueous solutions were prepared with deionized water. All other chemicals were purchased from Sigma-Aldrich unless stated otherwise.

\section{Preparation of $\mathrm{Gt}$}

Gt was prepared as described earlier. ${ }^{32,40,41}$ Briefly, Gt dispersion was obtained by sonication of Gt powders (synthetic, $<20 \mu \mathrm{m}$ ) in deionized water using a sonicator for 1 hour.

\section{Preparation of GtO}

Preparation of $\mathrm{GtO}$ was carried out as described earlier. ${ }^{42}$ Eight grams of $\mathrm{K}_{2} \mathrm{~S}_{2} \mathrm{O}_{8}, 8 \mathrm{~g}$ of $\mathrm{P}_{2} \mathrm{O}_{5}$, and $24 \mathrm{~mL}$ of $98 \% \mathrm{H}_{2} \mathrm{SO}_{4}$ were mixed in a $200 \mathrm{~mL}$ beaker and then heated to $80^{\circ} \mathrm{C}$ in a water bath. One gram of $\mathrm{Gt}$ powder (synthetic, $<20 \mu \mathrm{m}$ ) was added to the mixture and kept at $80^{\circ} \mathrm{C}$ for 6 hours. Then the mixture was diluted using distilled water and filtered through $0.20 \mu \mathrm{m}$ nylon membrane, followed by thorough washing with water and drying. Afterwards, the as-treated dry Gt powder was added to $368 \mathrm{~mL}$ of $\mathrm{H}_{2} \mathrm{SO}_{4}$ in an ice bath. Sixty grams of $\mathrm{KMnO}_{4}$ were added slowly with stirring. The mixture was heated to $40^{\circ} \mathrm{C}$ under vigorous stirring and kept for 1 hour. Next, $736 \mathrm{~mL}$ of water was slowly added; 15 minutes later, $2240 \mathrm{~mL}$ of water and $40 \mathrm{~mL} \mathrm{H}_{2} \mathrm{O}_{2}$ were added. Finally, GtO powder was suspended in distilled water, and metal ions and acids were removed by dialysis.

\section{GO synthesis}

GO was prepared from Gt powder using a modified method of Hummers and Offeman. ${ }^{40-43} \mathrm{Gt}$ powder $(2 \mathrm{~g})$ was mixed with $80 \mathrm{~mL} \mathrm{H}_{2} \mathrm{SO}_{4}$ and $20 \mathrm{~mL} \mathrm{HNO}_{3}$ in an ice bath. $\mathrm{KMnO}_{4}(12 \mathrm{~g})$ was slowly added to the mixture. The solution was heated at $35^{\circ} \mathrm{C}$ for 30 minutes, and then diluted with $160 \mathrm{~mL}$ of $18 \mathrm{M} \Omega$ water. In 1 hour, the solution was further diluted by adding $400 \mathrm{~mL}$ of $18 \mathrm{M} \Omega$ water, followed by the slow addition of $12.0 \mathrm{~mL}$ of $\mathrm{H}_{2} \mathrm{O}_{2}(30 \% \mathrm{v} / \mathrm{v})$. After these steps, the black Gt suspension was converted into a bright-yellow GtO solution. The precipitate of GO was isolated by centrifugation at 3000 $\mathrm{rpm} /$ minute for 15 minutes and washed with and then re-suspended in 18-M $\Omega$ water. The aqueous GO solution was then sonicated for 2 hours to facilitate the exfoliation of stacked $\mathrm{GtO}$ sheets into monolayer or multilayered GO sheets. The as-prepared GO yellow-brown solution $(\mathrm{mg} / \mathrm{mL})$ was used for further experiments.

\section{Reduction of GO}

The reduction of GO was performed as described earlier, ${ }^{40}$ with modification. Reduced GO was obtained from the reaction of BME with GO. Typically, the final concentration of $10 \mathrm{mM}$ of BME was dissolved in $20 \mathrm{~mL}$ GO aqueous suspension $(0.1 \mathrm{mg} / \mathrm{mL})$, and then the mixture was kept in a tightly sealed glass bottle and stirred at $60^{\circ} \mathrm{C}$ for 2 hours. Firstly, the black product was isolated by centrifugation at $5000 \mathrm{rpm} /$ minute for 10 minutes, and then $200 \mu \mathrm{L}$ of $10 \mathrm{~N} \mathrm{NaOH}$ aqueous solution was added into the product to dissolve black precipitate. Then the solution was centrifuged at 10,000 rpm/minute, and the obtained black slurry was washed with adequate deionized water and ethanol up to $\mathrm{pH}=7.0$. Finally, one part of the as-prepared product was dissolved in water to prepare the suspension of BME$\mathrm{rGO}$, and suspended rGO was used for further analysis.

\section{Characterization}

Ultraviolet-visible (UV-Vis) spectra were obtained using a WPA Biowave II (Biochrom Cambridge, UK). The aqueous suspension of GO and rGO was used as the UV-vis sample, and the deionized water was used as the reference. The particle size of dispersions was measured by a Zetasizer Nano ZS90 (Malvern Instruments, Malvern, UK). A refractive index $(\mathrm{n}=1.3)$ matching bath of filtered $(0.2 \mu \mathrm{m})$ surrounded the scattering cell, and the temperature was fixed at $25^{\circ} \mathrm{C}$. X-ray diffraction (XRD) analyses were carried out on an X-ray diffractometer (Bruker D8 Discover; Bruker, Karlsruhe, Germany). The high-resolution XRD patterns were measured at $3 \mathrm{Kw}$ with $\mathrm{Cu}$ target using a scintillation counter $\left(\lambda=1.5406^{\circ} \mathrm{A}\right)$ at $40 \mathrm{kV}$ and $40 \mathrm{~mA}$ and recorded in the range of $2 \vartheta=5^{\circ}-80^{\circ}$. A JSM-6700F semi-in-lens field-emission scanning electron microscope (JEOL, Tokyo, Japan) operating at $10 \mathrm{kV}$ was used to acquire scanning electron microscopy (SEM) images. The solid samples were transferred to a carbon tape and held in an SEM sample holder for analyses. The analyses of the samples were carried out at an average working distance of $6 \mathrm{~mm}$. Raman spectra of GO and rGO were measured by an Alpha300 (WITec, Ulm, Germany) with a $532 \mathrm{~nm}$ laser and $100 \times$ objective lens mounted on an Olympus (Tokyo, Japan) optical microscope. The calibration was initially made using an internal silicon reference at $500 \mathrm{~cm}^{-1}$ and gave a peak-position resolution of less than $1 \mathrm{~cm}^{-1}$. The spectra were measured from 500 to $4500 \mathrm{~cm}^{-1}$. All samples were deposited on glass slides in powder form without using any solvent. 


\section{Media and bacterial growth analysis}

Briefly, P. aeruginosa cultures were first grown aerobically at $37^{\circ} \mathrm{C}$ in Luria-Bertani (LB) broth containing tryptone $10 \mathrm{~g}$, yeast extract $5 \mathrm{~g}$, and $\mathrm{NaCl} 10 \mathrm{~g} / \mathrm{L}$. The cells were harvested by centrifugation, then washed twice with phosphate-buffered saline (PBS; pH 7.3) and resuspended in the appropriate fresh medium, such as the LB or saline, to bring the desired initial optical density. Inoculated cultures were grown in a shaker $(120 \mathrm{rpm})$ in $50 \mathrm{~mL}$ tubes (medium volume/tube volume $-1 / 10$ ) at $37^{\circ} \mathrm{C}$ until they reached the stationary phase. Growth was monitored spectrophotometrically by periodic measuring of the absorbance at $600 \mathrm{~nm}$. The bacteria were routinely maintained on LB agar slants and preserved in glycerol stock solutions at $-70^{\circ} \mathrm{C}$. Unless otherwise stated, three independent runs were made for all experiments.

\section{Turbidity assay}

Bacterial growth was measured as turbidity at $\mathrm{OD}_{600}$ using the WPA Biowave II. The P. aeruginosa was treated with $\mathrm{Gt}, \mathrm{GtO}, \mathrm{GO}$, and rGO in LB medium. The untreated sample was used as a control. The treated and untreated samples were measured at a single wavelength, $600 \mathrm{~nm}$, at 3-hour intervals. After the incubation of cells with graphene materials, cells were spun down at $5000 \mathrm{rpm}$ for 10 minutes and the supernatant (soluble graphene materials) removed and pellet (bacterial cells) redissolved in PBS. Three independent runs were made for all experiments.

\section{Cell preparation}

P. aeruginosa was grown in Luria-Bertani (LB) medium at $37^{\circ} \mathrm{C}$ and harvested in the midexponential growth phase. Cultures were centrifuged at $5000 \mathrm{rpm} /$ minute for 10 minutes to pellet cells. Then cells were washed three times with isotonic saline solution to remove residual macromolecules and other growth-medium constituents. Then the pellets were resuspended in isotonic saline solution. Bacterial cell suspensions were diluted up to the desired concentration of $10^{6}$ colony forming units $/ \mathrm{mL}$.

\section{Cell-viability test}

Bacterial growth after treatment was measured by quantifying cell viability after incubation with two different graphene materials. $P$. aeruginosa cells were incubated with fresh GO and rGO from $0,25,50,75,100,125$, and $150 \mu \mathrm{g} / \mathrm{mL}$ in isotonic saline solutions at $37^{\circ} \mathrm{C}$ under $200 \mathrm{rpm}$ shaking speed for 2 hours. After the treatment, $100 \mu \mathrm{L}$ of reaction mixture was made up to $1 \mathrm{~mL}$, and then from $1 \mathrm{~mL}, 50 \mu \mathrm{L}$ was taken for plating. Loss of viability was evaluated by the colony-counting method. Briefly, a series of 20 -fold cell dilutions ( $100 \mu \mathrm{L}$ each) were spread onto LB plates and left to grow overnight at $37^{\circ} \mathrm{C}$. Colonies were counted and compared with those on control plates to calculate changes in cell-growth inhibition. For control, we used isotonic saline solution without graphene-based materials. All treatments were prepared in triplicate and repeated at least in three independent experiments.

\section{Measurement of ROS generation}

ROS generation was determined using nitro blue tetrazolium (NBT) reduction assay, as described previously, ${ }^{44}$ with minor modifications. Briefly, ROS generation was determined in extracts from bacterial cells grown in liquid cultures. Bacteria $(0.1 \mathrm{~mL})$ suspension $\left(\mathrm{OD}_{600} 1.0\right)$ in Hanks' buffered salt solution was incubated with $0.1 \mathrm{~mL}$ of GO and rGO $(100 \mu \mathrm{g} / \mathrm{mL})$ for 2 hours and $0.5 \mathrm{~mL}$ of $1 \mathrm{mg} / \mathrm{mL}$ NBT for 30 minutes at $37^{\circ} \mathrm{C}$. Then $0.1 \mathrm{~mL}$ of $0.1 \mathrm{M} \mathrm{HCl}$ was added and the tubes were centrifuged at $1500 \mathrm{~g}$ for 10 minutes. The blue color of the supernatants was measured at $560 \mathrm{~nm}$ (ROS extracellular). The separated pellets were treated with $0.6 \mathrm{~mL}$ dimethyl sulfoxide to extract the reduced NBT. Finally, $0.8 \mathrm{~mL}$ Hanks' buffered salt solution was added, and the optical density was determined at $560 \mathrm{~nm}$ (ROS intracellular). Cells were pretreated with $\mathrm{N}$-acetylcysteine (NAC) and reduced glutathione (GSH) to a final concentration of $1 \mathrm{mM}$. Positive control for ROS generation was obtained by the addition of $\mathrm{H}_{2} \mathrm{O}_{2}$ to a final concentration of $3 \mathrm{mM}$.

\section{DNA fragmentation}

P. aeruginosa cells were grown in LB medium, washed with PBS buffer, and resuspended in PBS at a concentration of $2 \times 10^{8}$ viable cells. The cells were incubated with $100 \mu \mathrm{g} / \mathrm{mL}$ of $\mathrm{GO}, \mathrm{rGO}$, and silver nanoparticles (NPs) for 24 hours. Then the cells were lysed in $250 \mu \mathrm{L}$ cell lysis buffer containing $50 \mathrm{mM}$ Tris- $\mathrm{HCl}, \mathrm{pH} 8.0,10 \mathrm{mM}$ ethylenediaminetetraacetic acid, $0.1 \mathrm{M} \mathrm{NaCl}$, and $0.5 \% \mathrm{SDS}$. The lysate was incubated with $0.5 \mathrm{mg} / \mathrm{mL}$ RNase A at $37^{\circ} \mathrm{C}$ for 1 hour, and then with $0.2 \mathrm{mg} / \mathrm{mL}$ proteinase $\mathrm{K}$ at $50^{\circ} \mathrm{C}$ overnight. Phenol extraction of this mixture was performed, and DNA in the aqueous phase was precipitated by $25 \mathrm{~mL}$ $(1 / 10 \mathrm{vol})$ of $7.5 \mathrm{M}$ ammonium acetate and $250 \mathrm{~mL}$ (1/1 vol) isopropanol. DNA electrophoresis was performed in $1 \%$ agarose gel containing $1 \mathrm{mg} / \mathrm{mL}$ ethidium bromide at $70 \mathrm{~V}$, and the DNA fragments were visualized by exposing the gel to UV light, followed by photography. 


\section{Results and discussion \\ Characterization of GO and rGO by UV-Vis spectroscopy}

Figure 1 shows Gt, GtO, GO, and rGO produced by the modified method of Hummers and Offeman, ${ }^{40}$ and shows the dispersion of Gt, GtO, GO, and rGO at a concentration of $600 \mu \mathrm{g} / \mathrm{mL}$. The GO dispersion was obtained by the oxidation of GtO, and it is opaque yellow in color (Figure 1C); the resulting solution is clear and is a homogeneous yellow-brown GO dispersion. The obtained GO and $\mathrm{rGO}$ are appearing differently because of their distinct structural and physicochemical properties. ${ }^{3,32}$ The change of color from brown to dark indicates a reduction of GO. The aqueous dispersions of $\mathrm{GO}$ and the resulting rGO reveal a distinct color change from pale-yellow to black after chemical reduction. Such observations provide evidence to support the formation of rGO. ${ }^{45,46}$ The changing of color is due to the large amount of hydrophilic functional groups, such as carboxyl, hydroxyl, and epoxy groups, on GO nanosheets. ${ }^{3,32}$ After the visibility check, the reduction of GO was determined by UV-Vis spectroscopy. As shown in Figure 2, a UV-Vis spectrum shows that pure GO shows two absorption peaks: one at $<230 \mathrm{~nm}$, presumably due to the $\pi \rightarrow \pi^{*}$ transition of the $\mathrm{C}-\mathrm{C}$ bonds, and another shoulder at $<300 \mathrm{~nm}$ corresponds to the $n \rightarrow \pi^{*}$ transition of the $\mathrm{C}=\mathrm{O}$ bonds. ${ }^{45-47}$ While reducing by BME, the plasma peak gradually red-shifts to $260 \mathrm{~nm}$, suggesting that GO is reduced and the electronic conjugation within graphene sheets is restored upon BME reduction, reflecting increased $\pi$-electron concentration and structural ordering, which is

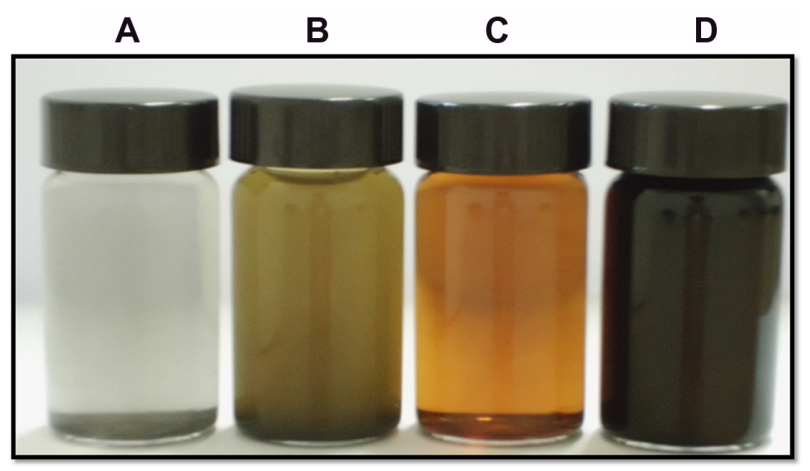

Figure I (A-D) Digital photograph of $\mathrm{Gt}, \mathrm{GtO}, \mathrm{GO}$, and $\mathrm{rGO}$ at a concentration of $600 \mu \mathrm{g} / \mathrm{mL}$. Gt, GtO, GO, and rGO were prepared as described in the Materials and methods section. Gt dispersion was obtained after sonication for I hour (A). The $\mathrm{GtO}$ dispersion was obtained by the oxidation of $\mathrm{Gt}$, and it is opaque yellow in color (B). GO nanosheets were exfoliated from the $\mathrm{GtO}$, resulting in the clearest and homogeneous yellow-brown GO dispersion (C). rGO was obtained from the reaction of BME with graphene oxide, resulting in the homogeneous dark color (D). Abbreviations: Gt, graphite; GtO, graphite oxide; GO, graphene oxide; rGO, reduced graphene oxide; BME, betamercaptoethanol.

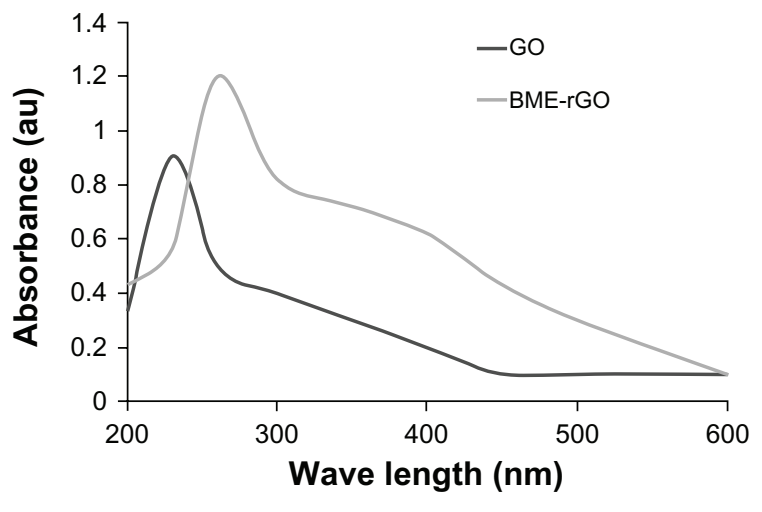

Figure 2 Ultraviolet-visible (UV-Vis) spectra of GO and rGO showing the restoration of electronic conjugation in the $\mathrm{rGO}$.

Notes: The reduction was measured by UV-Vis spectroscopy at ambient temperature by using a UV-Vis spectrophotometer. GO shows two absorption peaks: one at $\sim 230 \mathrm{~nm}$ and another shoulder at $\sim 300 \mathrm{~nm}$. After reduction by BME, the peak at $230 \mathrm{~nm}$ shifted to $260 \mathrm{~nm}$.

Abbreviations: GO, graphene oxide; rGO, reduced graphene oxide; BME, betamercaptoethanol.

consistent with the restoration of $s p^{2}$ carbon and possible rearrangement of atoms. ${ }^{48,49}$ Similar features and trends were observed for the reduction of GO with L-ascorbic acid ${ }^{26,50}$ and L-cysteine. ${ }^{26,42}$ In addition, UV-Vis spectra analysis shows a shoulder at $400 \mathrm{~nm}$ in $\mathrm{rGO}$, which suggests an emission peak due to BME.

\section{XRD analysis}

The distance between two layers is an important parameter to evaluate the structural information of the graphene. ${ }^{42}$ The XRD patterns of GO and rGO reduced by BME are compared and shown in Figure $3 \mathrm{~A}$ and B. Due to the presence of oxygen-containing functional groups attached on both sides of the graphene sheet and the atomic-scale roughness arising from structural defects ( $s p^{3}$ bonding) generated on the originally atomically flat graphene sheet, ${ }^{3}$ the $d$-spacing of the GO (Figure $3 \mathrm{~A}$ ) is about $0.76 \mathrm{~nm}\left(2 \vartheta \approx 11.7^{\circ}\right)$, after reduction of GO by BME, and the (002) peak of GO gradually disappears, whereas the broad diffraction peak was observed from $24^{\circ}$ to $29^{\circ}(d \approx 0.35 \mathrm{~nm})$. This shift in the interlayer spacing can be attributed to the reduction of the GO, where the reduction makes the $\mathrm{rGO}$ pack tighter than the GO (Figure 3B). ${ }^{7}$ Though there is a decrease in the interlayer spacing compared with $\mathrm{GO}$, the basal spacing of rGO is higher than that of well-ordered Gt (single-layer pristine graphene). The higher basal spacing may be due to the presence of residual oxygen functional groups, indicating incomplete reduction of GO. The fact that (002) reflection in these samples is very broad suggests that the samples are very poorly ordered along the stacking 

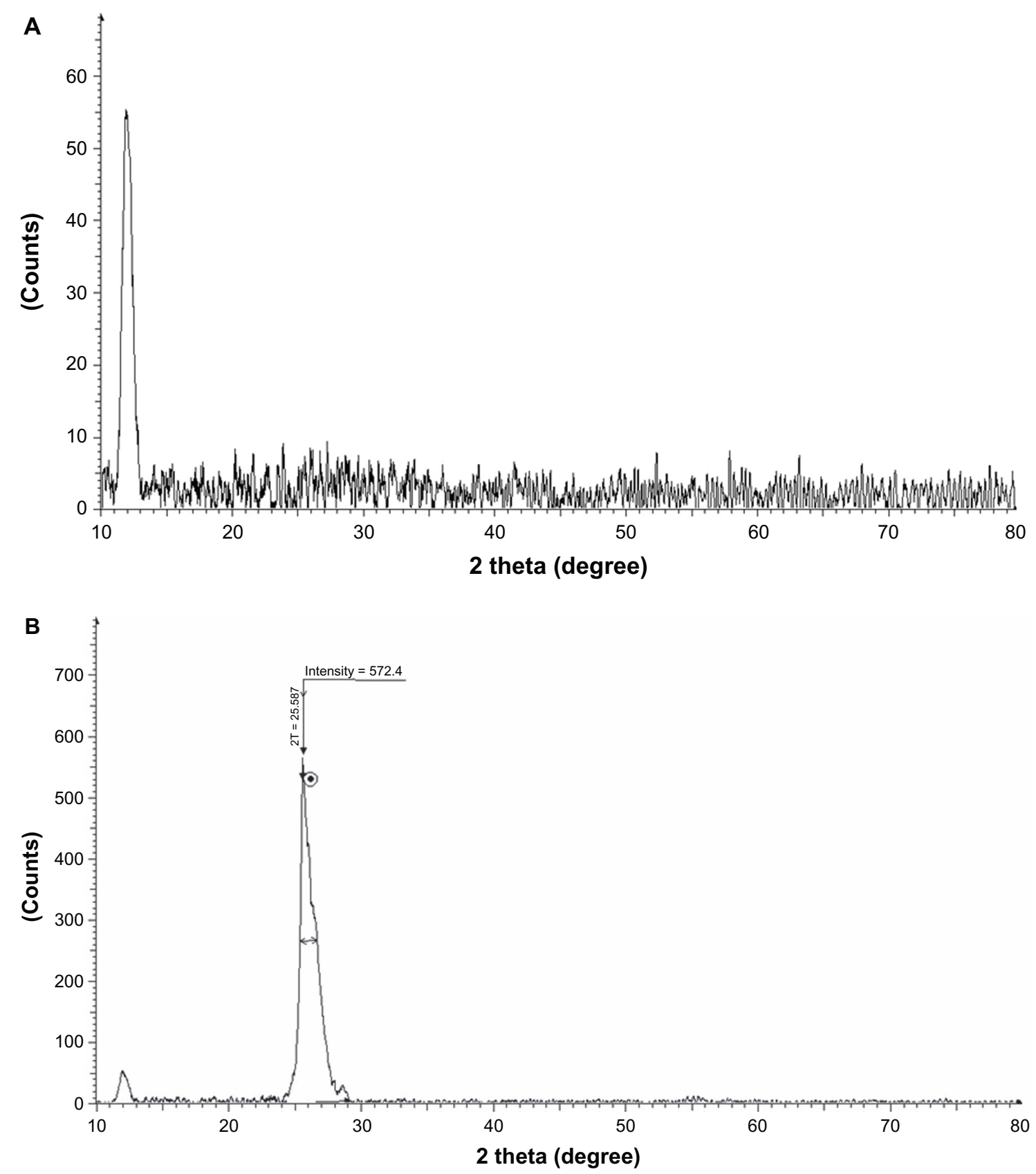

Figure 3 (A and B) X-ray diffraction (XRD) pattern of GO and rGO. In the XRD pattern of GO, the strong and sharp peak at $2 \theta=11.7^{\circ}$ corresponds to an interlayer distance of $7.6 \AA(\mathrm{d002})$ (A). rGO shows two peaks: one small peak centered at $2 \theta=11.7^{\circ}$ and another broad peak at $2 \theta=25.8^{\circ}$, corresponding to interlayer distances of 4.47 and $3.53 \AA$, respectively $(\mathbf{B})$.

Note: These XRD results are related to the exfoliation and reduction processes of $\mathrm{GO}$ and the processes of removing intercalated water molecules and the oxide groups. Abbreviations: GO, graphene oxide; rGO, reduced graphene oxide.

direction. It indicates that these samples comprise largely free rGO nanosheets. ${ }^{51}$ Similarly, Shen et al ${ }^{52}$ observed after reduction a gradual change in the patterns to finally accomplish a randomly ordered carbonaceous layered solid, with basal spacing of $0.34 \mathrm{~nm}$ instead of $0.78 \mathrm{~nm}$ for the parent GO, indicating that the bulk of the oxygencontaining functional groups is removed from GO. GO has a large interlayer distance due to the formation of hydroxyl, epoxy, and carboxyl groups. After reduction, the interlayer distance decreases due to the removal of some oxygen-containing functional groups. This suggests the conjugated graphene network ( $s p^{2}$ carbon) is reestablished during the reduction process, which is associated with the ring-opening of the epoxides. The changes of structure during the reduction process are also reflected in the Raman spectra of GO and rGO. 


\section{Particle-size distribution}

Furthermore, we characterized the aqueous dispersions of GO and rGO by using DLS at the scattering angle $\theta=90^{\circ}$. The standard spherical particle models were used in DLS. The size of GO (Figure 4A) and rGO (Figure 4B) were $0.525 \mu \mathrm{m}$ and $3.40 \mu \mathrm{m}$ respectively. Our results are similar to the results obtained by Liu et $\mathrm{a}^{32}$ regarding the size of GO and rGO. As described earlier, because most graphene-based materials are not spherical particles, the model-derived diameters are not their real sizes. DLS results only show the size differences between the two materials.

\section{SEM analysis}

The dispersions were further dropped on aluminum foil, and dozens of SEM images were taken randomly for each sample. SEM images of GO (Figure 5A) sheets are smooth with small wrinkles and folded at the edges, and SEM images of reduced GO revealed that the material consists of stacked and aggregated, thin, crumpled sheets closely associated with each other and forming a disordered solid (Figure 5B) which also look rigid, with transparent plates and silk sheets.

\section{Raman spectral analysis}

Raman spectroscopy is considered to be a popular technique for characterization of the structural and electronic properties of graphene, including disorder and defect structures, defect density, and doping levels. ${ }^{53}$ Raman spectroscopy is highly sensitive to electronic structure, and has proven to be an essential tool for the characterization of carbon-based materials, especially $\mathrm{C}=\mathrm{C}$ double bonds that lead to high Raman intensities. ${ }^{54}$ Raman spectroscopy of graphene is generally characterized by two main features: the G-peak, which arises from first-order scattering of the $E_{2 g}$ phonon from $s p^{2}$ carbon atoms (generally observed at $1575 \mathrm{~cm}^{-1}$ ); and the D-peak $\left(1355 \mathrm{~cm}^{-1}\right)$, which arises from breathing mode of $\kappa$-point photons of $A_{1 g}$ symmetry. Our results show that the G-band and D-band of GO appear at $1595 \mathrm{~cm}^{-1}$ and $1347 \mathrm{~cm}^{-1}$, respectively (Figure 6A). The Raman spectrum of $\mathrm{GO}$, as expected, displays a prominent $\mathrm{G}$ (the $E_{2 \mathrm{~g}}$ mode of $s p^{2}$ carbon atoms) peak as the characteristic feature at $1595 \mathrm{~cm}^{-1}$. The Raman spectra further support the structural change before and after the reduction of GO by BME. In the Raman spectrum of GO after the reduction by BME, the D-band was

A

Size distribution by intensity

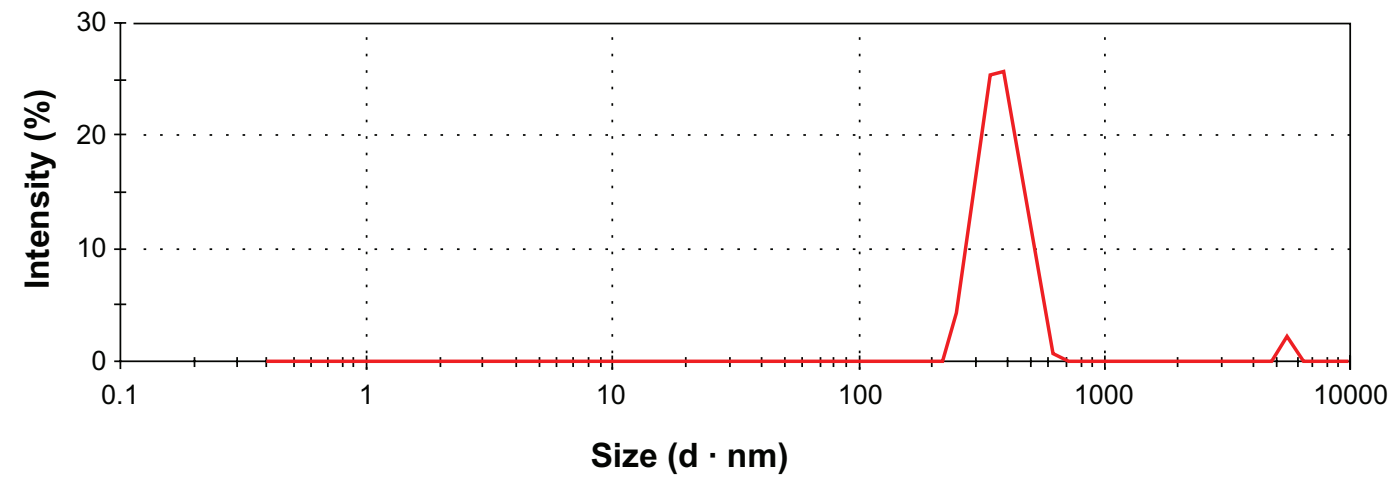

B

Size distribution by intensity

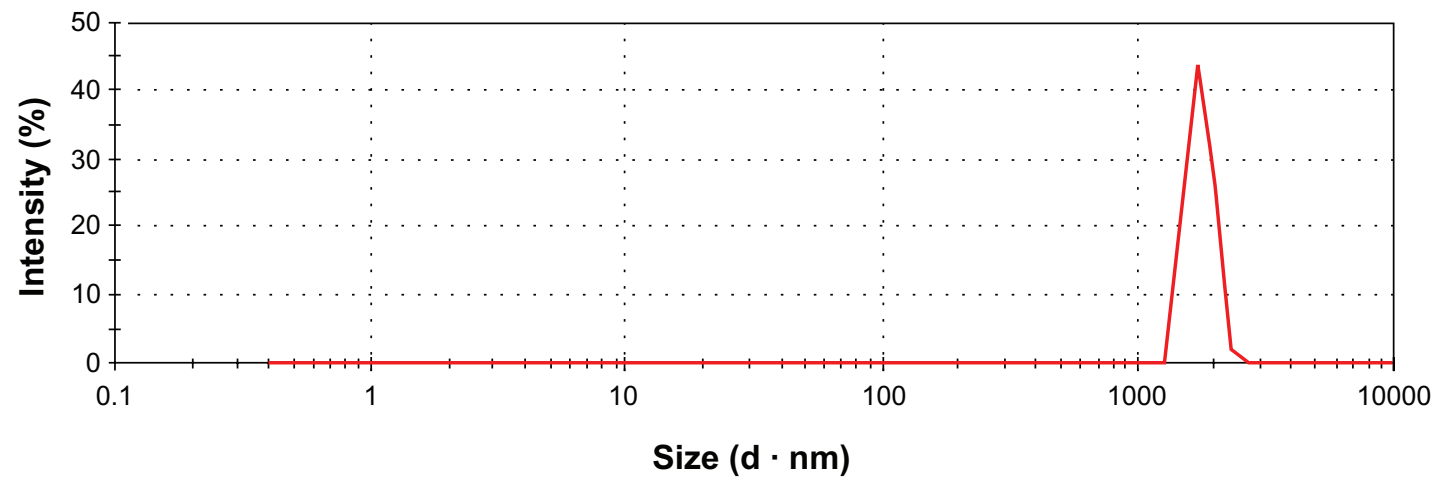

Figure 4 (A and B) Dynamic light-scattering (DLS) spectra of GO and rGO dispersions. At least 200 particles were measured for each sample to obtain the size distribution. The GO (A) and rGO (B) sizes were measured by a Zetasizer Nano ZS90 with a scattering angle $\theta=90^{\circ}$.

Notes: The standard spherical particle models were used in DLS. DLS results provide a quick indication of their different solubility.

Abbreviations: GO, graphene oxide; rGO, reduced graphene oxide. 
A

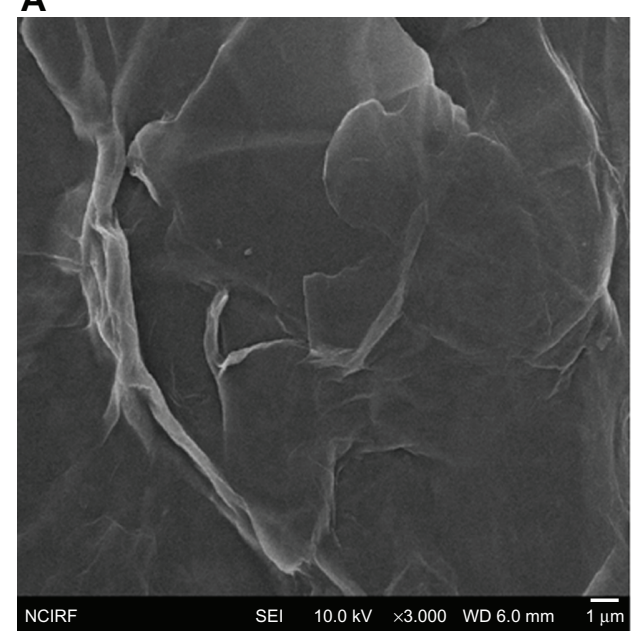

B

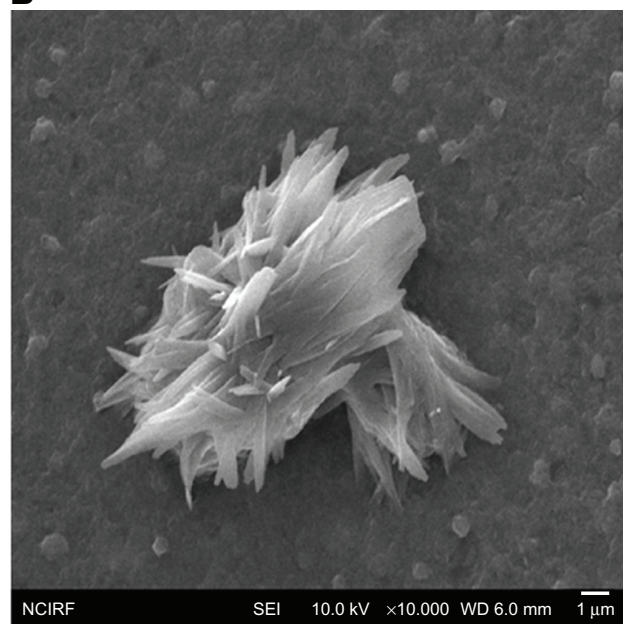

Figure 5 (A and B) Scanning electron microscopy images of GO and rGO. 0.I mg/mL of GO and rGO was dispersed in aluminum foil and dried, and then images were taken using scanning electron microscopy. GO sheets are smooth with small wrinkles and folded at the edges (A), and reduced GO material consists of stacked and aggregated, thin, crumpled sheets (B).

Abbreviations: GO, graphene oxide; rGO, reduced graphene oxide.

broadened and shifted to around $1342 \mathrm{~cm}^{-1}$ and the G-band shifted to $1603 \mathrm{~cm}^{-1}$ (Figure 6B). The D-band at $1342 \mathrm{~cm}^{-1}$ of $\mathrm{BME}$ became prominent, indicating the reduction in size of the in-plane $s p^{2}$ domains due to the extensive oxidation with BME. Interestingly, the Raman spectrum of GO after reduction by BME shows a higher $\mathrm{D} / \mathrm{G}$ intensity ratio than $\mathrm{GO}$. Compared to pure $\mathrm{GO}$, the $\mathrm{D} / \mathrm{G}$ ratio of the BME-reduced GO increased significantly (1.9), indicating the introduction of $s p^{3}$ defects after functionalization and incomplete recovery of the structure of graphene. ${ }^{55}$ The variation of relative intensities of the G-band and D-band in the Raman spectra of the GO during the reduction usually reveals the change of the electronic conjugation state. This change indicates an increase in the number of $s p^{2}$ domains after reduction of GO. ${ }^{49}$ This observation is in good agreement with previous findings, ${ }^{42}$ which revealed that sulfur containing amino acid, namely L-cysteine, used as reducing agent from GO to rGO nanosheets. Additionally, another study developed a green and a facile approach to synthesis of graphene nanosheets using reducing sugars. ${ }^{53}$
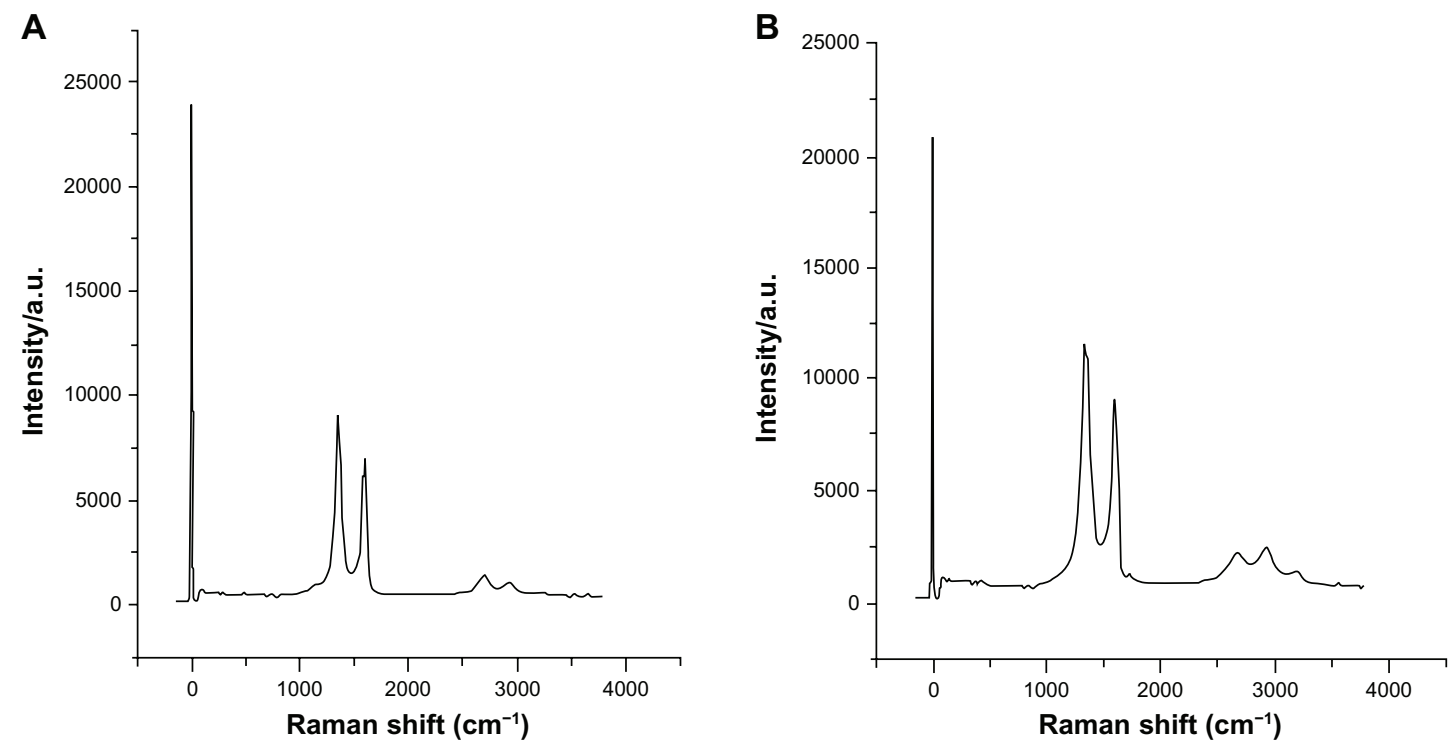

Figure 6 (A and B) Raman spectra of GO and rGO. The G-band and D-band of GO appear at I595 cm $\mathrm{cm}^{-1}$ and I347 $\mathrm{cm}^{-1}$, respectively (A). In the Raman spectrum of GO after the reduction by BME, (B) the D-band is broadened and shifted to around $1342 \mathrm{~cm}^{-1}$ and $\mathrm{G}$ band shifted to $1603 \mathrm{~cm}^{-1}$.

Note: $r G O$ after reduction by BME shows a higher D/G intensity ratio than GO.

Abbreviations: GO, graphene oxide; $\mathrm{FGO}$, reduced graphene oxide; BME, betamercaptoethanol. 


\section{Effect of Gt, GtO, GO, and rGO on bacterial growth}

Regarding graphene materials, there have been lots of contradictory reports about biocompatibility and antimicrobial activity. Recently, Ruiz et al $^{56}$ showed that bacteria grew faster and to a higher optical density when GO was added to a bacterial culture at $25 \mu \mathrm{g} / \mathrm{mL}$ than cultures without GO, and also they explained bacterial growth on filters coated with 25 and $75 \mu \mathrm{g}$ of GO grew two and three times better than on filters without GO. Liu et al ${ }^{32}$ observed strong antibacterial activity of four types of graphene-based materials (Gt, GtO, GO, and rGO). In addition, $\mathrm{Hu}$ et $\mathrm{al}^{24}$ employed a classic colony-counting method to measure the microbial viability of Escherichia coli treated with $85 \mu \mathrm{g} / \mathrm{mL}$ GO for 2 hours, and GO almost completely suppressed the growth of $E$. coli, leading to a significant loss of viability. In order to scrutinize efficient graphene materials for antibacterial activity in the presence of media components, we performed a systematic study with Gt, GtO, GO, and rGO in LB medium (rich medium) and LB medium without graphene material used as control.

First, we evaluated the growth curve of $P$. aeruginosa under aerobic conditions in LB medium with and without $\mathrm{Gt}, \mathrm{GtO}, \mathrm{GO}$, and $\mathrm{rGO}(75 \mu \mathrm{g} / \mathrm{mL})$ for 15 hours. As a result, $P$. aeruginosa control strains displayed identical exponential growth trends. In the early period of growth, Gt- and GtO-treated $P$. aeruginosa displayed a similar trend; however this started to decline in the late exponential phase. GO and rGO had a negative effect on bacterial growth, as the turbidity measurements decreased steadily over a 6-hour period. Interestingly, there was significant growth inhibition up to $92 \%$ after 15 hours' exposure to GO and rGO. As shown in Figure 7, GO and rGO had a significant effect on bacterial growth when compared to the control. The growth of $P$. aeruginosa decreased after treatment with GO and rGO. However, the rate of antibacterial activity of GO was higher than rGO. Our results concluded that Gt and GtO show lower antibacterial activity in comparison to GO and rGO. Therefore, our further experiments focused on only two graphene materials: GO and rGO.

\section{Concentration-dependent antibacterial activity of GO and rGO}

The concentration dependence of antibacterial activities on graphene-based materials were studied. GO or rGO dispersions at different concentrations $(0,25,50,75,100,125$,

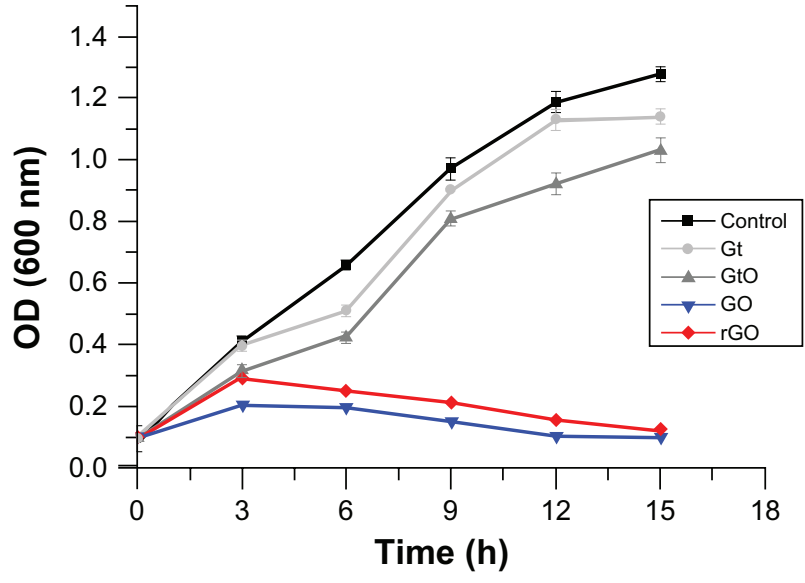

Figure 7 Effect of various graphene materials (Gt, GtO, GO, and rGO) on growth of Pseudomonas aeruginosa.

Notes: Cells were incubated with $\mathrm{Gt}, \mathrm{GtO}, \mathrm{GO}$, and rGO $(75 \mu \mathrm{g} / \mathrm{mL})$ separately. Samples were withdrawn at different time points of growth, and cells were centrifuged, washed with distilled water, and analyzed for growth at $600 \mathrm{~nm}$. Data are averages from triplicate experiments. Error bars represent standard deviations of triplicate incubations. The results represent the means of three separate experiments, and error bars represent the standard error of the mean. Treated groups showed statistically significant differences from the control group by Student's t-test $(P<0.05)$.

Abbreviations: Gt, graphite; GtO, graphite oxide; GO, graphene oxide; rGO, reduced graphene oxide.

150,175 , and $200 \mu \mathrm{g} / \mathrm{mL}$ ) were incubated with $P$. aeruginosa cells for 2 hours at $37^{\circ} \mathrm{C}$. As shown in Figure 8, the loss of $P$. aeruginosa viability progressively goes up with increases of $\mathrm{GO}$ or $\mathrm{rGO}$ concentration. When the cells were exposed to $\mathrm{GO}$ and $\mathrm{rGO}$, significant loss of viability was observed at concentrations of 75 and $100 \mu \mathrm{g} / \mathrm{mL}$, respec-

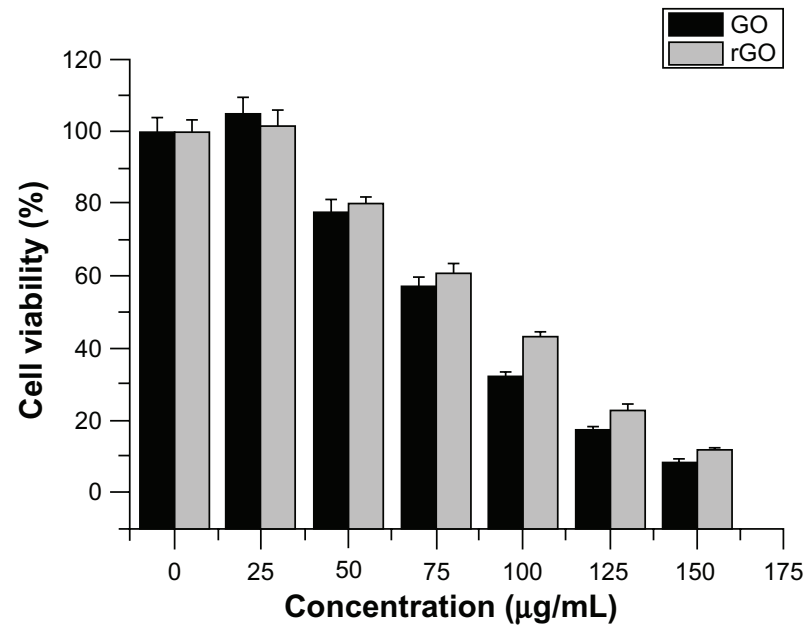

Figure 8 Effect of concentration-dependent GO and rGO in Pseudomonas aeruginosa cell viability.

Notes: Cells were incubated at $37^{\circ} \mathrm{C}$ with various concentrations of GO and rGO separately for 2 hours at $200 \mathrm{rpm}$ shaking speed. Cell-viability rates were determined by the colony-counting method and expressed as a percentage of control. The results represent the means of three separate experiments, and error bars represent the standard error of the mean. Treated groups showed statistically significant differences from the control group by Student's $t$-test $(P<0.05)$. Abbreviations: GO, graphene oxide; rGO, reduced graphene oxide. 
tively. However, maximum loss of $P$. aeruginosa viability was detected after incubation with $150 \mu \mathrm{g} / \mathrm{mL}$ of $\mathrm{GO}$ and rGO. In both graphene materials, there was no colony observed over concentrations of $175 \mu \mathrm{g} / \mathrm{mL}$. These results suggest that antibacterial activities of graphene-based materials are also concentration- and material-dependent. As suggested earlier, regarding the GO antibacterial mechanism, cellular damage of $P$. aeruginosa might arise from the effects of either oxidative stress or physical disruption that have been observed in the cellular effects of related carbon nanomaterial CNTs and fullerene. ${ }^{24}$ Recently, Liu et $\mathrm{al}^{32}$ demonstrated that most $E$. coli cells become flattened and lose their cellular integrity after exposure to GO or rGO dispersions. This highlights that irreversible damage can be induced in bacterial cells after direct contact with graphene-based materials. Our results further agree with previous findings by other research teams, ${ }^{24,25,32}$ where it was proven that graphene materials exert the same effect on Gram-negative bacteria.

\section{Time-dependent antibacterial activity of GO and rGO}

We examined the time-dependent antibacterial efficiency of $\mathrm{GO}$ and $\mathrm{rGO}$. GO and $\mathrm{rGO}$ dispersions $(75 \mu \mathrm{g} / \mathrm{mL})$ were incubated with $P$. aeruginosa with equal concentration of cell biomass. The loss of $P$. aeruginosa viability was counted at

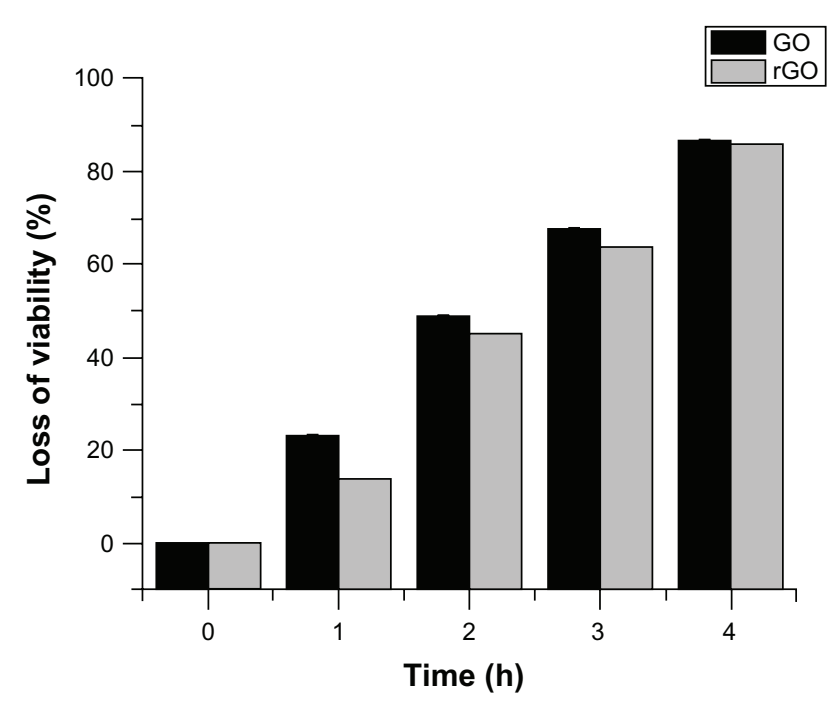

Figure 9 Time-dependent antibacterial activities of GO and rGO.

Notes: Pseudomonas aeruginosa $\left(10^{6}-10^{7}\right.$ colony forming units $\left./ \mathrm{mL}\right)$ cells were treated with GO or $\mathrm{rGO}(100 \mu \mathrm{g} / \mathrm{mL})$ at $37^{\circ} \mathrm{C}$ for 4 hours at $200 \mathrm{rpm}$ shaking speed. Cell-viability rates were determined by the colony-counting method and expressed as a percentage of control. The results represent the means of three separate experiments, and error bars represent the standard error of the mean. Treated groups showed statistically significant differences from the control group by Student's $t$-test $(P<0.05)$.

Abbreviations: GO, graphene oxide; $\mathrm{rGO}$, reduced graphene oxide. different time points: 1, 2, 3, and 4 hours (Figure 9). The loss of $P$. aeruginosa viability increased after 1-hour incubation with GO and rGO from $0 \%$ to $23 \%$ and $14 \%$, respectively. By increasing the incubation time, the loss of viability increased to $49 \%$ and $40 \%$ for 2 -hour incubation. Finally, after 4 -hour incubation, the loss of $P$. aeruginosa viability was $87 \%$ and $86 \%$ treated with $\mathrm{GO}$ and $\mathrm{rGO}$, respectively. The division of cell death occurred in all 4 hours of incubation; however, a large fraction of cell death occurred in the earlier hour of incubation. Our results revealed that comparing $\mathrm{GO}$ and $\mathrm{rGO}$ dispersions, GO dispersions have much higher antibacterial activity than rGO dispersions at all tested incubation intervals.

\section{Oxidative stress induced by GO and rGO}

Oxidative stress is a highly recognized mechanism of various NPs. A systematic study was performed to evaluate the toxicity/biocompatibility of GO to A549 cells, a widely used model cell line for toxicity studies. ${ }^{37}$ Recent studies have indicated that GO is highly biocompatible; however, some studies reported that GO has a higher toxicity to cells and animals at high concentrations, ${ }^{24,57,58}$ and found that $\mathrm{GO}$ is toxic to human fibroblast cells at concentrations of $50 \mu \mathrm{g} / \mathrm{mL}$ and higher, which is due to the structural and physiochemical properties of carbon nanomaterials such as fullerene, which induce oxidative stress as a key antibacterial mechanism, ${ }^{29}$ and CNTs. ${ }^{59,60}$ Liu et al ${ }^{32}$ concluded that based on XTT (sodium 2,3,-bis[2-methoxy-4-nitro-5-sulfophenyl]5-[phenylamino-carbonyl]-2 $H$ tetrazolium inner salt) results, graphene-based materials mediate a little superoxide anion production and a trace amount of ROS may be produced; this plays a minor role in the antibacterial activity of graphenebased materials. To investigate ROS production as one of the key factors for cell death, we measured ROS levels using NBT assay. The levels of ROS in GO and rGO treated cells were 3.8-fold and 2.7-fold higher, respectively, compared to the level of ROS in control cells throughout the experiment (Figure 10). Since $\mathrm{H}_{2} \mathrm{O}_{2}$ induced ROS, it was employed as a positive control. $\mathrm{H}_{2} \mathrm{O}_{2}$ led to a 5.6-fold increase in ROS levels compared to the level of ROS in the control. Reduced GSH is an important molecule for protecting cells from toxic compounds, and intracellular GSH levels can be increased by the antioxidant compound NAC. Thus, we tested if preincubation of cells with GSH or NAC could prevent ROS generation by GO and $\mathrm{rGO}$, and found that these intracellular antioxidants protected $P$. aeruginosa from GO and rGO (Figure 10) and reduced the levels of ROS in GO- and rGO-treated cells. Taken together, all these results indicate that cell death is mediated by ROS production, which might 


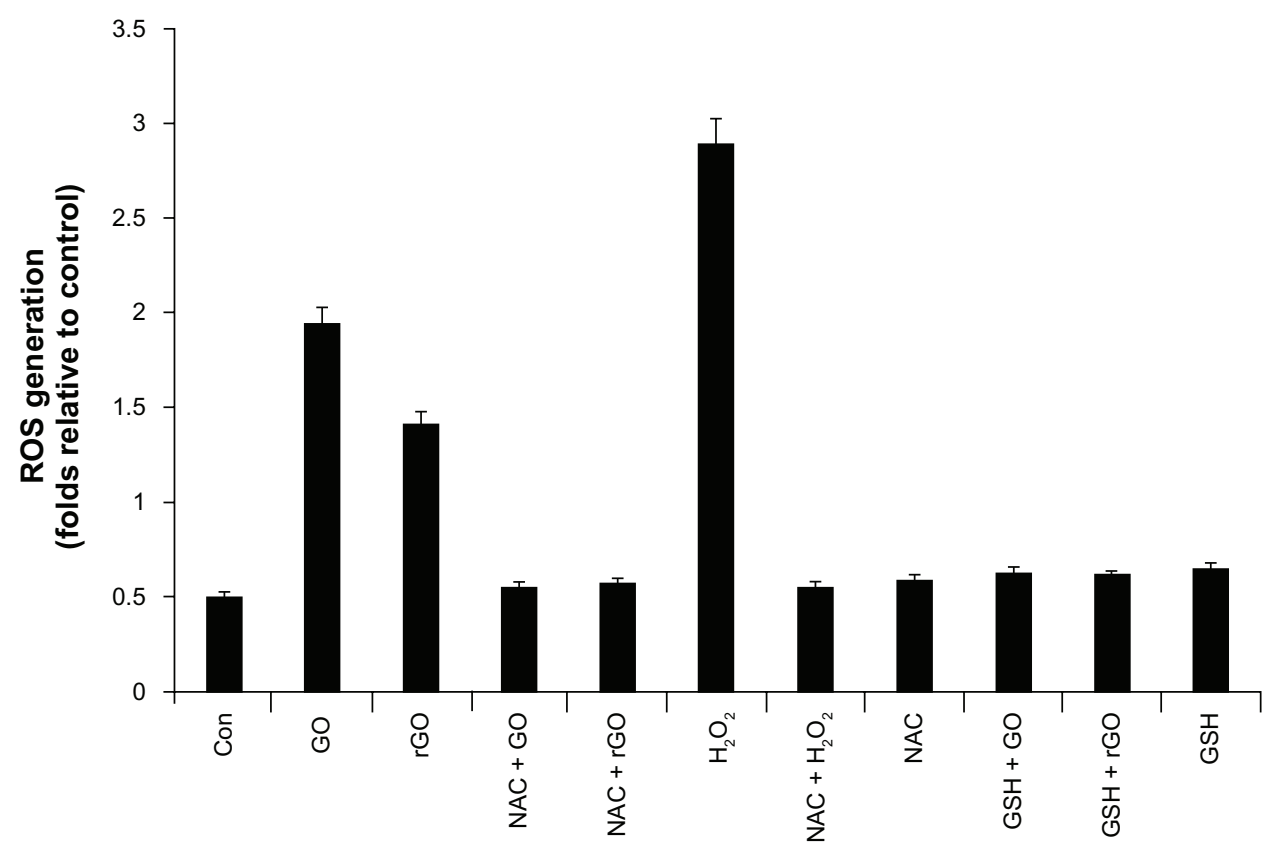

Figure 10 Effect of GO and rGO on ROS generation in Pseudomonas aeruginosa.

Notes: ROS generation was measured by nitro blue tetrazolium (NBT) assay. Cells were treated separately with GO and rGO (I00 $\mu$ g/mL) for 2 hours. Cells were pretreated with NAC and GSH to a final concentration of I mM. NBT reduction was stopped by adding acetic acid to the incubation medium. Reduced NBT was dissolved in dimethyl sulfoxide, and the absorbance was determined at $560 \mathrm{~nm}$. The results represent the means of three separate experiments, and error bars represent the standard error of the mean. Treated groups showed statistically significant differences from the control group by Student's $t$-test $(P<0.05)$. Positive control for ROS generation was obtained by the addition of $\mathrm{H}_{2} \mathrm{O}_{2}$ to a final concentration of $3 \mathrm{mM}$.

Abbreviations: GO, graphene oxide; rGO, reduced graphene oxide; ROS, reactive oxygen species; NBT, nitro blue tetrazolium; NAC, N-acetylcysteine; GSH, glutathione.

alter the cellular redox status. Akhavan and Ghaderi ${ }^{25}$ suggested that the higher bacterial toxicity of the reduced nanowalls was attributed to more sharpening of the edges of the nanowalls, providing stronger contact interaction with the cell membrane and/or better charge transfer between the bacteria and the reduced nanowalls, resulting in more cell membrane damage of the bacteria.

\section{DNA fragmentation}

To elucidate the mechanism of cell death induced by GO and rGO, we chose DNA fragmentation assay, which is a good indicator of cellular dysfunction. Oxidative stress and ROS generation were revealed to be some of the key mechanisms in cellular defense after particle uptake. Intracellular oxidative stress could be hastened by NPs by disturbing the equilibrium between the oxidant and antioxidant processes. ${ }^{59,60}$ ROS typically include the superoxide radical $\left(\mathrm{O}^{2-}\right)$, hydrogen peroxide $\left(\mathrm{H}_{2} \mathrm{O}_{2}\right)$, and hydroxyl radical $(\mathrm{OH})$, which cause damage to cellular components, including DNA and proteins. ${ }^{61,62}$ ROS generation is also an important factor in the apoptosis process, and the excess generation of ROS induces mitochondrial membrane permeability and damages the respiratory chain to trigger the apoptotic process. ${ }^{63,64}$ Specific DNA smearing is a characteristic feature of cell death. In order to examine whether ROS generation by graphene materials leads to DNA damage in $P$. aeruginosa, DNA was extracted from $P$. aeruginosa cells treated with $100 \mu \mathrm{g} / \mathrm{mL}$ GO and rGO for 24 hours and analyzed for the occurrence of DNA fragmentation. The results show that the cells treated with GO for 24 hours show laddering of DNA, but rGO and silver NPs did not show significant fragmentation (Figure 11), which suggests that cells require longer time exposure of rGO to generate DNA fragmentation or that the mechanism of cell death caused by rGO could be different from GO. Recently, Akhavan et al ${ }^{65}$ demonstrated that the reduced GO nanoplatelets-PEG exhibited concentrationdependent cyto- and genotoxicity (resulting in $>72 \%$ cell destruction and $>29 \%$ DNA fragmentation after 24 hours in the dark) in human glioblastoma cell line U87MG. The potential effect of GO on DNA fragmentation is due to irreversible damages that can be induced in bacterial cells after direct contact with GO. Liu et al ${ }^{32}$ demonstrated that most $E$. coli cells were individually wrapped with thin layers of GO nanosheets. In contrast, $E$. coli cells were usually embedded in large rGO aggregates. The different behavior of GO and rGO suggests the aggregation/dispersion of graphene-based materials may play an important role in their antibacterial activities. ${ }^{32}$ Akhavan and Ghaderi ${ }^{25}$ suggest that 


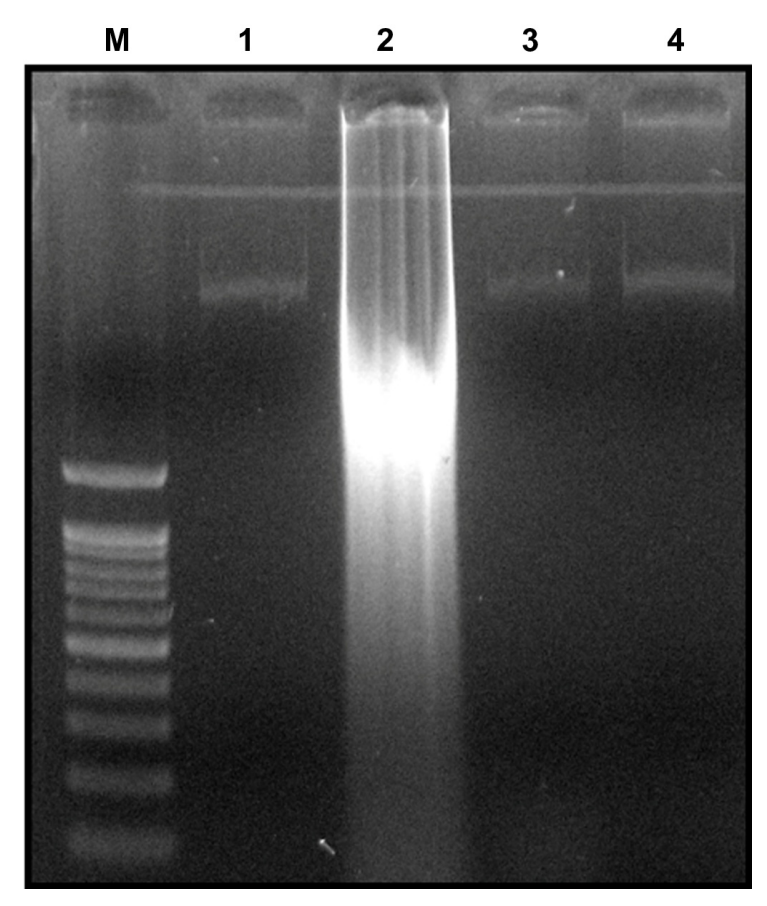

Figure II Detection of GO and rGO induced apoptosis by cellular DNA fragmentation.

Notes: For DNA fragmentation, cells were incubated with GO and rGO $(100 \mu \mathrm{g} / \mathrm{mL})$ for 24 hours. After incubation, DNA extracted from cells and resolved on agarose gel electrophoresis. Lane M, I kB ladder; lane I, control; lane 2, GO; lane 3, rGO; lane 4, silver nanoparticles.

Abbreviations: GO, graphene oxide; rGO, reduced graphene oxide.

that the direct-contact interaction of the bacteria with the very sharp edge of the nanowalls resulted in more damage to the cell membrane of the Gram-positive Staphylococcus aureus bacteria lacking the outer membrane compared to the Gram-negative $E$. coli ones owning the outer membrane. From our results, we concluded that the antibacterial activity of GO and rGO not only depends on density of functional groups, size, conductivity, and the amount of cells deposited on graphene-based materials but also membrane oxidative stress caused by direct contact with sharp nanosheets, and the generation of ROS and DNA fragmentation consequently leads to cell death. Further studies are required to address which factors are playing an important role in the antibacterial activity of $\mathrm{GO}$ and $\mathrm{rGO}$.

\section{Conclusion}

Among various nanomaterials, graphene is a novel carbonbased nanomaterial, and has attracted a great deal of attention due to its remarkable physical, chemical, and biological characteristics. The results presented here demonstrate the antibacterial activity of GO and rGO against $P$. aeruginosa. $\mathrm{rGO}$ was synthesized from GO using BME as a novel reducing agent, which is nontoxic when compared to hydrazine. The novelty of this work includes the antibacterial activity of GO and rGO being evaluated in systematic analysis of cell growth and cell viability using saline and rich medium and explored. GO and rGO showed significant antibacterial activity in a concentration- and time-dependent manner. Further, our results demonstrated that oxidative stress is a key mechanism for the antibacterial activity of GO and rGO through ROS generation. This study opens an exciting opportunity for the use of graphene materials as an antibacterial agent.

\section{Acknowledgments}

This paper was supported by the SMART-Research Professor Program of Konkuk University. Dr Sangiliyandi Gurunathan was supported by a Konkuk University SMART full-time professorship. This work was supported by the Woo Jang Choon Project (PJ009107) and the next generation of Biogreen 21 (PJ00816903) from the Rural Development Administration (RDA), South Korea.

\section{Disclosure}

The authors report no conflicts of interest in this work.

\section{References}

1. Kroto HW, Heath JR, O'Brien SC, Curl RF, Smalley REC. $\mathrm{C}_{60}$ : buckminsterfullerene. Nature. 1985;318:162-163.

2. Mauter MS, Elimelech M. Environmental applications of carbon-based nanomaterials. Environ Sci Technol. 2008;42:5843-5859.

3. Stankovich S, Dikin DA, Piner RD, et al. Synthesis of graphene-based nanosheets via chemical reduction of exfoliated graphite oxide. Carbon. 2007;45:1558-1565.

4. Geim KA, Novoselov KS. The rise of graphene. Nat Mater. 2007;6: 183-191.

5. Geim AK. Graphene: status and prospects. Science. 2009;324: 1530-1534.

6. Novoselov KS, Geim AK, Morozov SV, Jiang D, ZhangY, Dubonos SV. Electric field effect in atomically thin carbon films. Science. 2004;306:666-669.

7. Park S, Ruoff RS. Chemical methods for the production of graphenes. Nat Nanotechnol. 2009;4:217-224.

8. Compton OC, Nguyen ST. Graphene oxide, highly reduced graphene oxide, and graphene: versatile building blocks for carbon-based materials. Small. 2010;6:711-723.

9. Luo Z, Yu T, Shang J, Wang Y, Lim S, Liu L. Large-scale synthesis of bi-layer graphene in strongly coupled stacking order. Adv Funct Mater. 2011;21:911-917.

10. Rao CNR, Sood AK, Subrahmanyam KS, Govindaraj A. Graphene: the new two-dimensional nanomaterial. Angew Chem Int Ed Engl. 2009;48:7752-7777.

11. Yang K, Zhang S, Zhang G, Sun X, Lee ST, Liu Z. Graphene in mice: ultrahigh in vivo tumor uptake and efficient photothermal therapy. Nano Lett. 2010;10:3318-3323.

12. Kostarelos K, Bianco A, Prato M. Promises, facts and challenges for carbon nanotubes in imaging and therapeutics. Nat Nanotechnol. 2009;4:627-633.

13. Liu Z, Tabakman S, Welsher K, Dai H. Carbon nanotubes in biology and medicine: in vitro and in vivo detection, imaging and drug delivery. Nano Res. 2009;2:85-120. 
14. Huang YX, Palkar PV, Li LJ, Zhang H, Chen P. Integrating carbon nanotubes and lipid bilayer for biosensing. Biosens Bioelectron. 2010;25:1834-1837.

15. Yang K, Wan J, Zhang S, Zhang Y, Lee ST, Liu Z. In vivo pharmacokinetics, long-term biodistribution, and toxicology of PEGylated graphene in mice. ACS Nano. 2010;5:516-522.

16. Sun X, Liu Z, Welsher K, et al. Nano-graphene oxide for cellular imaging and drug delivery. Nano Res. 2008;1:203-212.

17. Liu Z, Robinson JT, Sun XM, Dai HJ. PEGylated nanographene oxide for delivery of water-insoluble cancer drugs. J Am Chem Soc. 2008;130:10876-10877.

18. Wang K, Ruan J, Song H, et al. Biocompatibility of graphene oxide. Nanoscale Res Lett. 2011;10:8.

19. Akhavan O, Ghaderi E, Aghayee S, Fereydooni Y, Talebi A. The use of a glucose-reduced graphene oxide suspension for photothermal cancer therapy. J Mater Chem. 2012;22:13773-13781.

20. Yang K, Hu L, Ma X, et al. Multimodal imaging guided photothermal therapy using functionalized graphene nanosheets anchored with magnetic nanoparticles. Adv Mater. 2012;24:1868-1872.

21. Hu SH, Chen YW, Hung WT, Chen IW, Chen SY. Quantum-dot-tagged reduced graphene oxide nanocomposites for bright fluorescence bioimaging and photothermal therapy monitored in situ. Adv Mater. 2012;24: 1748-1754.

22. Ma X, Tao H, Yang $\mathrm{K}$, et al. A functionalized graphene oxide-iron oxide nanocomposite for magnetically targeted drug delivery, photothermal therapy, and magnetic resonance imaging. Nano Res. 2012;5:199-212.

23. Park S, Mohanty N, Suk JW, Nagaraja A, An JH, Piner RD Biocompatible, robust free-standing paper composed of a TWEEN/ graphene composite. Adv Mater. 2010;22:1736-1740

24. Hu WB, Peng C, Luo WJ, et al. Graphene-based antibacterial paper ACS Nano. 2010;4:4317-4323.

25. Akhavan O, Ghaderi E. Toxicity of graphene and graphene oxide nanowalls against bacteria. ACS Nano. 2010;4:5731-5736.

26. Zhang JL, Yang HJ, Shen GX, Cheng P, Zhang JY, Guo SW. Reduction of graphene oxide via L-ascorbic acid. Chem Commun. 2010;46: 1112-1114.

27. Liu J, Yang L, Hopfinger AJ. Affinity of drugs and small biologically active molecules to carbon nanotubes: a pharmacodynamics and nanotoxicity factor? Mol Pharm. 2009;6:873-882.

28. Kang X Wang J, Wu H, Aksay I, Liu J, Lin Y. Glucose oxidasegraphene-chitosan modified electrode for direct electrochemistry and glucose sensing. Biosens Bioelectron. 2009;25:901-905.

29. Lyon DY, Brunet L, Hinkal GW, Wiesner MR, Alvarez PJJ. Antibacterial activity of fullerene water suspensions $(\mathrm{nC}(60))$ is not due to ROS-mediated damage. Nano Lett. 2008;8:1539-1543.

30. Fang M, Zhang Z, Li J, Zhang H, Lu H, Yang Y. Constructing hierarchically structured interphases for strong and tough epoxy nanocomposites by amine-rich graphene surfaces. J Mater Chem. 2010;20: 9635-9643.

31. Kang S, Pinault M, Pfefferle LD, Elimelech M. Single-walled carbon nanotubes exhibit strong antimicrobial activity. Langmuir. 2007;23: 8670-8673.

32. Liu S, Zeng TH, Hofmann M, Burcombe E, Wei J, Jiang R. Antibacterial activity of graphite, graphite oxide, graphene oxide, and reduced graphene oxide: membrane and oxidative stress. ACS Nano. 2011;5:96971-96980.

33. Arias LR, Yang LJ. Inactivation of bacterial pathogens by carbon nanotubes in suspensions. Langmuir. 2009;25:3003-3012.

34. Obraztsova EA, Lukashev EP, Zarubina AP, Parkhomenko IM, Yaminsky IV. Bactericidal action of single-walled carbon nanotubes. Phys Bull. 2009;64:320-323.

35. Liao KH, Lin YS, MacOsko CW, Haynes CL. Cytotoxicity of graphene oxide and graphene in human erythrocytes and skin fibroblasts. ACS Appl Mater Interfaces. 2011;3:2607-2615.

36. Zhang Y, Ali SF, Dervishi E, et al. Cytotoxicity effects of graphene and single-wall carbon nanotubes in neural phaeochromocytoma-derived PC12 cells. ACS Nano. 2010;4:3181-3186.
37. Chang Y, Yang ST, Liu JH, et al. In vitro toxicity evaluation of graphene oxide on A549 cells. Toxicol Lett. 2011;200:201-210.

38. Akhavan O, Ghaderi E, Esfandiar A. Wrapping bacteria by graphene nanosheets for isolation from environment, reactivation by sonication and inactivation by near-infrared irradiation. $J$ Phys Chem B. 2011;115:6279-6288.

39. Akhavan O, Ghaderi E, Akhavan A. Size-dependent genotoxicity of graphene nanoplatelets in human stem cells. Biomaterials. 2012; (32):8017-8025.

40. Hummers WS, Offeman RE. Preparation of graphitic oxide. JAm Chem Soc. 1958;80:1339.

41. Chen D, Li L, Guo L. Environment-friendly preparation of reduced graphene oxide nanosheets via amino acid. Nanotechnology. 2011;22:325-601.

42. Liu L, Liu W, Hong T, Weng X, Zhai Q, Zhou X. $\mathrm{Ag}^{+}$and cysteine detection by $\mathrm{Ag}^{+}$-guanine interaction based on graphene oxide and G-quadruplex DNA. Anal Methods. 2012;4:1935-1939.

43. Wang G, Qian F, Saltikov CW, Jiao Y, Li Y. Microbial reduction of graphene oxide by Shewanella. Nano Res. 2011;4:563-570.

44. Becerra MC, Albesa I. Oxidative stress induced by ciprofloxacin in Staphylococcus aureus. Biochem Biophys Res Commun. 2002;297:1003-1007.

45. McAllister MJ, Li LJ, Adamson DH, et al. Single sheet functionalized graphene by oxidation and thermal expansion of graphite. Chem Mater. 2007;19:4396-4404.

46. Luo Z, Lu Y, Somers LA, Johnson ATC. High yield preparation of macroscopic graphene oxide membranes. J Am Chem Soc. 2009;131:898-899.

47. Khanra TP, Kuila T, Kim N, Bae S, Yu DS, Lee JH. Simultaneous biofunctionalization and reduction of graphene oxide by baker's yeast. Chem Eng J. 2012;183:526-533.

48. Kuila T, Bose S, Khanra P, Mishra AK, Kim NH, Lee JH. Recent advances in graphene-based biosensors. Biosens Bioelectron. 2011;26:4637-4648.

49. Eda, Chhowalla M. Chemically derived graphene oxide: towards large-area thin film electronics and opto-electronics. Adv Mater. 2010;22:2392-2415

50. Fernandez-Merino MJ, Guardia L, Paredes JI, Villar-Rodil S, Solis-Fernandez P, Martinez-Alonso A. Vitamin C is an ideal substitute for hydrazine in the reduction of graphene oxide suspensions. $J$ Phys Chem C Nanomater Interfaces. 2010;114:6426-6432.

51. Nethravathi C, Rajamathi M. Chemically modified graphene sheets produced by the solvothermal reduction of colloidal dispersions of graphite oxide. Carbon. 2008;46:1994-1998.

52. Shen J, Hu Y, Shi M, et al. Fast and facile preparation of graphene oxide and reduced graphene oxide nanoplatelets. Chem Mater. 2009;21:3514-3520.

53. Zhu C, Guo S, Fang Y, Dong S. Reducing sugar: new functional molecules for the green synthesis of graphene nanosheets. ACS Nano. 2010;4:2429-2437.

54. Niyogi S, Bekyarova E, Itkis ME, Zhang H, Shepperd K, Hicks J. Spectroscopy of covalently functionalized graphene. Nano Lett. 2010;10:4061-4066.

55. Kudin KN, Ozbas B, Schniepp HC, Prud'homme RK, Aksay IA, Car R. Raman spectra of graphite oxide and functionalized graphene sheets. Nano Lett. 2008;8:36-41.

56. Ruiz ON, Fernando KA, Wang B, Brown NA, Luo PG, McNamara ND. Graphene oxide: a nonspecific enhancer of cellular growth. ACS Nano. 2011;5:8100-8107.

57. Agarwal S, Zhou X, Ye F, He Q, Chen GCK, Soo J. Interfacing live cells with nanocarbon substrates. Langmuir. 2010;26:2244-2247.

58. Vecitis CD, Zodrow KR, Kang S, Elimelech M. Electronic-structuredependent bacterial cytotoxicity of single-walled carbon nanotubes. ACS Nano. 2010;4:5471-5479.

59. Kang S, Herzberg M, Rodrigues DF, Elimelech M. Antibacterial effects of carbon nanotubes: size does matter. Langmuir. 2008;24: 6409-6413. 
60. Nel A, Xia T, Madler L, Li N. Toxic potential of materials at the nano level. Science. 2006;311:622-627.

61. Park EJ, Choi J, Park Y, Park K. Oxidative stress induced by cerium oxide nanoparticles in cultured BEAS-2B cells. Toxicology. 2008;245:90-100.

62. Foster KA, Galeffi F, Gerich FJ, Turner DA, Muller M. Optical and pharmacological tools to investigate the role of mitochondria during oxidative stress and neurodegeneration. Prog Neurobiol. 2006;79: 136-171.
63. Ott M, Gogvadze V, Orrenius S, Zhivotovsky B. Mitochondria, oxidative stress and cell death. Apoptosis. 2007;12:913-922.

64. Valko M, Rhodes CJ, Moncol J, Izakovic M, Mazur M. Free radicals, metals and antioxidants in oxidative stress-induced cancer. Chem Biol Interact. 2006;160:1-40.

65. Akhavan O, Ghaderi E, Emamy H. Nontoxic concentrations of PEGylated graphene nanoribbons for selective cancer cell imaging and photothermal therapy. Mater. Chem.2012;22:20626-20633.

\section{Publish your work in this journal}

The International Journal of Nanomedicine is an international, peerreviewed journal focusing on the application of nanotechnology in diagnostics, therapeutics, and drug delivery systems throughout the biomedical field. This journal is indexed on PubMed Central, MedLine, CAS, SciSearch $\AA$, Current Contents ${ }^{\circledR} /$ Clinical Medicine,
Journal Citation Reports/Science Edition, EMBase, Scopus and the Elsevier Bibliographic databases. The manuscript management system is completely online and includes a very quick and fair peer-review system, which is all easy to use. Visit http://www.dovepress.com/ testimonials.php to read real quotes from published authors. 